\title{
Mosquito Longevity, Vector Capacity, and Malaria Incidence in West Timor and Central Java, Indonesia
}

\author{
Ermi Ndoen, ${ }^{1}$ Clyde Wild, ${ }^{1,2}$ Pat Dale,,${ }^{1,2}$ Neil Sipe, ${ }^{1,3}$ and Mike Dale ${ }^{1}$ \\ ${ }^{1}$ Griffith School of Environment, Griffith University, Nathan, QLD 4222, Australia \\ ${ }^{2}$ Environmental Futures Centre, Griffith University, Nathan, QLD 4111, Australia \\ ${ }^{3}$ Urban Research Program, Griffith University, Nathan, QLD 4111, Australia \\ Correspondence should be addressed to Neil Sipe, n.sipe@griffith.edu.au \\ Received 6 September 2011; Accepted 11 October 2011 \\ Academic Editor: G. Tolomiczenko
}

Copyright (c) 2012 Ermi Ndoen et al. This is an open access article distributed under the Creative Commons Attribution License, which permits unrestricted use, distribution, and reproduction in any medium, provided the original work is properly cited.

The aim of this paper was to relate anopheline mosquito longevity to malaria incidence in two areas in Indonesia: West Timor and Central Java. We estimated the physiological age of females captured landing on humans or resting inside and outside buildings. The estimate was based on the state of the ovaries and was used to estimate longevity. The results showed that there were large differences between the two areas surveyed. In West Timor the longevity of the anophelines ranged from 13 to 23 days, sufficient for completing the intrinsic incubation cycle and for malaria transmission, whereas in Central Java the longevity was only 3 days, insufficient both for incubation and for transmission. We concluded that the West Timor study area had a greater risk of malaria transmission than that of Central Java and this was supported by village survey data that showed greater malaria incidence in West Timor than in Central Java.

\section{Introduction}

Malaria is a life-threatening disease in Indonesia with an estimated 15 million cases and 42,000 deaths every year [1-3]. It is transmitted by infected Anopheles mosquitoes. Although there are 24 Anopheles species recorded throughout Indonesia [4-6], not all are important in malaria transmission.

The most extensively occurring species of anopheline mosquitoes in Indonesia are An. sundaicus, An. subpictus, An. barbirostris, An. maculatus, An. aconitus, and An. bablabacensis, $[5,7]$ and all are implicated in malaria transmission.

Malaria transmission has a complex parasite life cycle which depends on both humans and mosquitoes [8]. In the mosquito, the malarial parasite (Plasmodium spp.) develops an exogenous sexual phase (sporogony cycle). When the sporozoites have developed, they make their way to the mosquito saliva glands, from which they are transmitted to humans via the mosquito bite. Malaria develops in a new cycle within the human host. An infective mosquito is a prerequisite for malaria transmission. It takes between 8 and
35 days to complete the parasite's life cycle in the mosquito host, depending on the condition of the environment and the species of malaria parasites [9-11].

Takken et al. [5] highlighted important factors for mosquitoes to become malaria vectors. These include mosquito density, behavioural factors, and vectorial capacity. Behavioural characteristics include feeding habits, anthropophily or zoophily [12]; house-frequenting resting habits, exophily or endophily [13]; and site of feeding, endophagy or exophagy [12]. Vectorial capacity and the ability to transmit malaria is related to mosquito longevity and susceptibility to Plasmodium infection.

Previous research has addressed some of these factors: that is, the significant habitats and the dusk-to-dawn pattern of host-seeking activity of the main malaria vectors in West Timor and Java $[14,15]$. The aim here was to explore a simple method of assessing the longevity, by age grading, of anopheline mosquitoes in West Timor and Central Java and relating this to vectorial capacity to help explain the different malaria incidences in the two areas. 


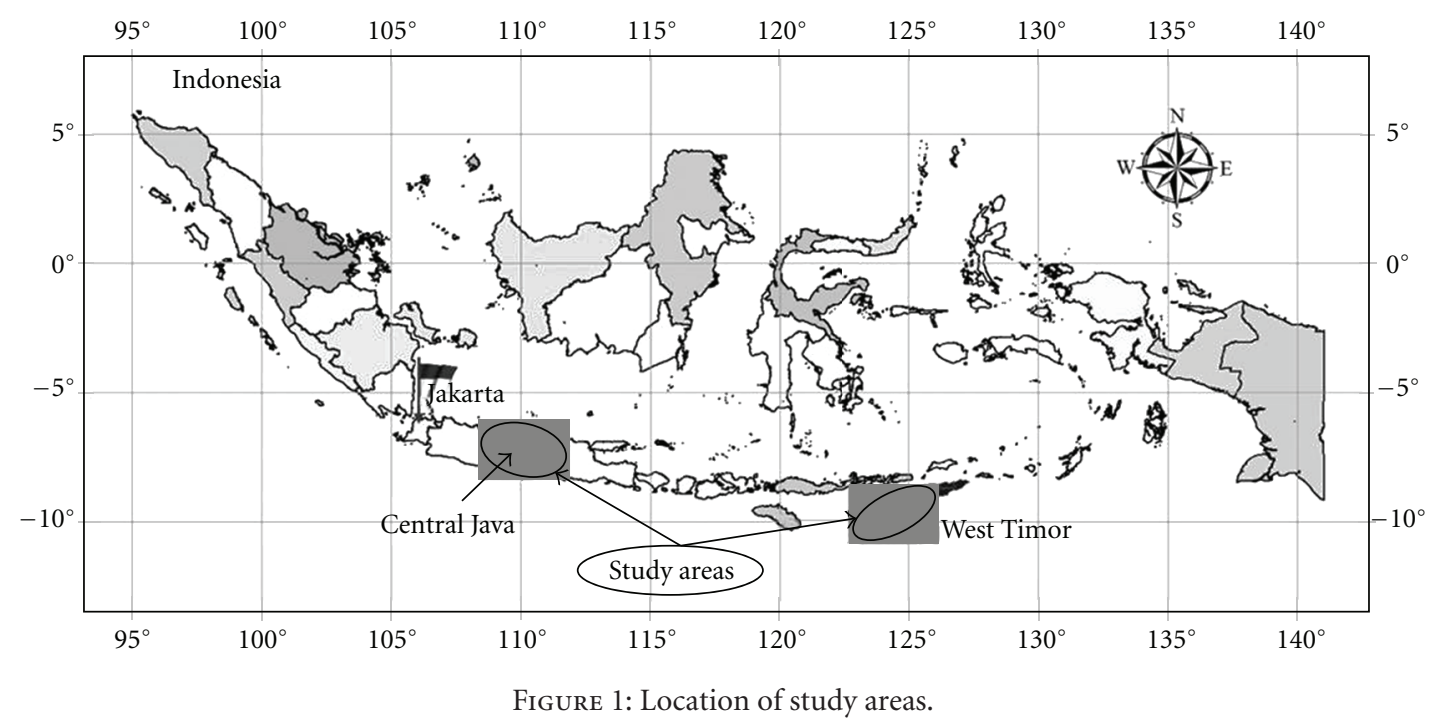

\section{Methods}

2.1. Study Areas and Malaria Incidence. Figure 1 shows the study areas in West Timor and Central Java. Seven villages (five in West Timor and two in Central Java) were chosen to represent coastal plain, hilly, and highland areas [14]. The villages were selected also for their pattern of malaria as recorded and by the availability of local assistants and access constraints. Data from another part of the research showed a significant difference in malaria incidence between Central Java and West Timor [16]. In Central Java only 24\% of 464 villages reported malaria cases between 2001 and 2006, whereas in West Timor all 701 villages reported malaria between 2003 and 2006. It also showed that Central Java was wetter than West Timor. For example, village data for 2005 shows a mean rainfall of $2867 \mathrm{~mm}$ (SD1019) for Central Java and $1839 \mathrm{~mm}$ (SD 325) for West Timor. This is referred to in Section 4.

2.2. Adult Mosquito Surveys. Adult mosquito surveys were conducted fortnightly based on the human landing count method recommended by WHO $[17,18]$. Table 1 provides details.

Human landing collections were conducted indoors and outdoors between 18:00 and 06:00. Adult mosquitoes were caught when landing on human volunteers' bare legs or hands during the night as well as those resting on walls. Details are in [14].

2.3. Mosquito Identification and Age-Grading Methods. The mosquitoes were identified to species, followed by examination of the abdominal condition of females for age grading. The mosquitoes were identified using the Anopheles taxonomic and identification key to female Anophelines of Indonesia provided by the Indonesian Ministry of Health [4].

Age grading was based on the mosquitoes physiological age $[12,19]$. The physiological age was determined from inspecting its ovaries, based on the technique described by Warrell and Gilles [12, page 80] as follows.

(1) The fresh killed mosquito was placed on a microscope slide with a drop of distilled water surrounding the posterior part of the abdomen.

(2) On the sixth or seventh segment, a cut was made in the abdomen and the contents were pulled out gently.

(3) The ovaries were transferred to the slides with a small drop of water and they were left to dry.

(4) The ovaries were then studied under the microscope to determine whether they were nulliparous or parous. The nulliparous condition is indicated by the tightly coiled endings to the tracheoles (skeins) while the parous female has uncoiled endings.

The female mosquitoes that have taken a blood meal and have laid their eggs at least once are parous, while those that have not taken a blood meal and laid their eggs are nulliparous. The parity rate $(\mathrm{PR})$ reflects the proportion of parous from the total number of ovaries dissected $[12,20]$.

2.4. Mosquito Life Expectancy (Longevity). Mosquito life expectancy or longevity was calculated using the formula proposed by Davidson [19]:

$$
\text { Age }=\frac{1}{\log \ell^{P}},
$$

where $\ell$ is the natural logarithm of the constant 2.7183 and $P$ is the probability of the vector surviving for 1 day. $P$ is calculated from the following formula:

$$
P=\sqrt[g c]{\mathrm{PR}}
$$

where gc is the Anopheles gonotrophic cycle: the time (days) needed by a female mosquito to complete the processing of egg development in the ovaries from the blood meal to the 
TABLE 1: Summary of mosquito surveys in West Timor and Central Java.

\begin{tabular}{lcl}
\hline Location (village) & No. of collector nights & Dates of survey \\
\hline West Timor & 12 & \\
Noelbaki & 12 & 21-Jun, 5-Jul 2006 \\
Tablolong & 18 & 20-Jul, 18-Aug 2006 \\
Liufeto-Tuadale & 36 & 2-Aug, 31-Aug, 28-Dec 2006 \\
Sikumana & 48 & 29-Jun, 13-Jul, 27-Jul, 24-Aug, 12-Sep 06, 05-Jan 2007 \\
Haumenbaki & 126 & 25-Jun, 07-Jul, 21-Jul, 3-Aug, 25-Aug, 21-Sep, 19-Oct, 3-Nov, 17-Nov, 30-Nov, \\
\hline Total West Timor & & 7-Dec, 14-Dec 2006 \\
\hline Central Java & 24 & 18-Jan, 2-Feb, 17-Feb, 3-Mar, 17-Mar, 31-Mar 2007 \\
Sadang Kulon & 24 & 18-Jan, 02-Feb, 17-Feb, 3-Mar, 17-Mar, 31-Mar 2007 \\
Jojogan & 48 & \\
\hline Total Central Java & 178 & \\
\hline Grand Total &
\end{tabular}

time when the fully developed eggs are laid $[12,19]$. PR is the rate of parous mosquitoes. In this study, gc was 3 days, based on a study of the importance of An. leucosphyrus group mosquitoes as vectors of malaria and filariasis in relation to transmigration and forestry in Indonesia [21, 22].

\section{Results}

3.1. Survey Summary. A total of 37 mosquito surveys were conducted from June 2006 to March 2007: 25 in West Timor and 12 in Central Java. Table 2 shows the species and numbers caught.

In West Timor, 1,626 mosquitoes were captured, giving an average of 65 mosquitoes per night or 4 mosquitoes per night per collector. There were six Anopheles species captured: An. aconitus, An. annularis, An. barbirostris, An. maculatus, An. subpictus, and An. vagus.

In Central Java, a total of 4,580 mosquitoes were collected during the surveys. The mosquito density was high with an average of 382 mosquitoes per night and 48 mosquitoes per night per collector. Nine Anopheles species were captured in Central Java: An. aconitus, An. annularis, An. flavirostris, An. kochi, An. maculatus, An. subpictus, An. tesselatus, and An. vagus.

3.2. Anopheles Parity Rate and Life Span. The parity rate (PR) and longevity or life span were analysed for West Timor and Central Java. PR was used to estimate mosquito life expectancy based on the formula proposed by Davidson [19]. Since there was no direct observation of the gonotrophic cycle (gc) value, the mosquito life expectancy calculation used a gc value of 3 days as explained previously.

3.3. West Timor. During the study, due to the small number of mosquitoes caught in some species, only three species, An. subpictus, An. barbirostris, and An. vagus, were used to calculate Anopheles life expectancy. The result is shown in Table 3. The life expectancy or age of Anopheles spp. in West
Timor was 23 days for An. subpictus, 21 days for An. vagus, and 13 days for An. barbirostris.

3.4. Central Java. Because of the small number of mosquitoes captured in Central Java only two species were used to calculate life expectancy (days). Table 4 shows that the Anopheles age was only a little more than 3 days for both $A n$. aconitus and An. vagus.

\section{Discussion}

4.1. Anopheles species Life Expectancy. Not all mosquitoes can transmit malaria to humans for several reasons: they do not feed on humans, they are not susceptible to the malaria parasite, and their life spans are too short to allow parasites to fully mature (Oaks et al.) [23]. However there are other important factors (assuming that a mosquito has been exposed to infection) that affect risk of infection for humans. One is the dusk-to-dawn host-seeking behaviour of mosquitoes and how that interacts with human activities. The dusk-to-dawn mosquito behaviour patterns have been explored for the study areas and these data enhance the findings from the present study and are referred to as follows [15].

In West Timor the average life expectancy of Anopheles spp. ranged from 13 to 20 days. Service and Towson [24] noted that the average duration life of female Anopheles in tropical areas is about 10-14 days and occasionally can reach 21 days [24]. Sandosham and Thomas also noted that the average life span of An. barbirostris under laboratory condition can reach 34 days [20]. In our research, of the three species with sufficient longevity for pathogen development, An. barbirostris was found inside dwellings and had peak activity during the night. This species thus poses a significant malaria risk during times when people are indoors and asleep. Bednets and indoor residual spraying would be a worthwhile strategy to control this mosquito species to reduce malaria risk. The other two West Timor species (An. 
TABLE 2: Total mosquitoes captured both landing and resting in West Timor and Central Java (species considered most important for malaria transmission are in bold).

\begin{tabular}{|c|c|c|c|c|c|c|}
\hline \multirow{2}{*}{ Anopheles species } & \multicolumn{2}{|c|}{ West Timor } & \multicolumn{2}{|c|}{ Central Java } & \multicolumn{2}{|c|}{ Grand total } \\
\hline & Mosquitoes & $\%$ & Mosquitoes & $\%$ & Mosquitoes & $\%$ \\
\hline \multicolumn{7}{|l|}{ Age graded } \\
\hline An. aconitus & 10 & 0.62 & 870 & 19 & 880 & 14.2 \\
\hline An. barbirostris & 247 & 15.2 & - & - & 247 & 3.98 \\
\hline An. subpictus & 1,065 & 65.5 & 415 & 9.06 & 1,480 & 23.8 \\
\hline An. vagus & 282 & 17.3 & 2,308 & 50.4 & 2,590 & 41.7 \\
\hline \multicolumn{7}{|l|}{ Others } \\
\hline An. annularis & 16 & 0.98 & 489 & 10.7 & 505 & 8.14 \\
\hline An. flavirostris & - & - & 4 & 0.09 & 4 & 0.06 \\
\hline An. indefinitus & - & - & 481 & 10.5 & 481 & 7.75 \\
\hline An. kochi & - & - & 9 & 0.2 & 9 & 0.15 \\
\hline An. maculatus & 6 & 0.37 & 1 & 0.02 & 1 & 0.02 \\
\hline An. tesselatus & - & - & 3 & 0.07 & 3 & 0.05 \\
\hline $\begin{array}{l}\text { Total mosquitoes } \\
\text { captured }\end{array}$ & 1,626 & 100 & 4,580 & 100 & 6,206 & 100 \\
\hline
\end{tabular}

TABLE 3: Anopheles age in West Timor (PR is parity rate; $P$ is probability of surviving 1 day).

\begin{tabular}{lcccccc}
\hline & & & Number of mosquitoes & & Age (days) \\
& Collected & Dissected & Parous & PR & 0.80 & 0.93 \\
An. barbirostris & $\mathbf{1 7 3}$ & 64 & 51 & 0.88 & 0.96 & 13.21 \\
An. subpictus & $\mathbf{6 9 3}$ & 244 & 214 & 0.87 & 0.95 & 22.87 \\
An. vagus & $\mathbf{9 8}$ & 92 & 80 & & 21.47 \\
\hline
\end{tabular}

TABle 4: Anopheles age in Central Java (PR is parity rate; $P$ is probability of surviving 1 day).

\begin{tabular}{lcccccc}
\hline \multirow{2}{*}{ Anopheles species } & & \multicolumn{3}{c}{ Number of mosquitoes } & Age (days) \\
& Collected & Dissected & Parous & PR & 0.40 & 0.74 \\
An. aconitus & $\mathbf{4 7}$ & 47 & 19 & 0.38 & 3.31 \\
An. vagus & $\mathbf{3 2}$ & 32 & 12 & 0.72 & 3.06 \\
\hline
\end{tabular}

subpictus and An. vagus) showed no preference for indoors or outdoors and their association with animal barns suggests that they may have zoophilic tendencies. To reduce exposure to these species human avoidance of outdoors at night would be a behavioural response to the risk, and source reduction may be a mosquito-control option.

In Central Java the life expectancy of the two Anopheles species was less than 4 days. This is in line with a recent study by Susanna [22], also in Central Java, who found a life span of 3.19 days for An. aconitus and 3.27 days for An. barbirostris. Another explanation may be that mosquito control was very effective and had killed many adults so that the mosquitoes caught were a new generation. However this is not very likely in the present instance, given the resource limitations on mosquito control and as collections were made over a range of time. Both species either had no preference for indoors or outdoors and An. vagus again was found resting in animal barns, suggesting a degree of zoophily. Control of these may benefit from source reduction where practicable.

Since the parasite needs time to develop in a mosquito (8-35 days), the longer the mosquito life span, the more effective the mosquito becomes as a vector [10]. Therefore, based on their average age, the three vectors (An. subpictus, An. vagus, and An. barbirostris) in West Timor would be more effective and have more potential to transmit malaria than the Anopheles spp. in Central Java. This contributes to the explanation as to why the disease in West Timor has an uninterrupted malaria transmission during the year, which keeps the incidence high, as noted earlier. In addition Warrell and Gilles noted that high-parous-rate mosquitoes are more common in drier areas or in dry season conditions [12]. West Timor is drier than Central Java. This weather condition might contribute to the longer life span in West Timor than in Central Java of the Anopheles. 
Finally the use of age grading may be a useful indicator for three reasons: (1) explaining the incidence of malaria; (2) assessing the potential risk of exposure to mosquitoes which may be infected with Plasmodium, and (3) helping to assess the effectiveness of mosquito control measures [25], young mosquitoes potentially indicating effective control (but with some provisos referred to previously).

\section{Conclusion}

There were large differences between the two areas surveyed in terms of mosquito longevity and this is one of the major determinants of malaria transmission. The results indicate that West Timor has a more severe malaria transmission risk than the Central Java study area and this is supported by information from a household survey, that showed a higher number of malaria episodes among households in West Timor than that in Central Java [16].

\section{Acknowledgments}

This research was supported by an Australian Research Council Discovery Grant (DP 0558908). The assistance of advisers in Indonesia: Professor Sugeng Mardihusodo (Gadjah Mada University), and Dr. Damar Tri Boewono (Vector and Disease Reservoirs Research Center, Salatiga, Central Java); the entomologists: Agus Samol (West Timor), Trisuwaryono, and Mujiyono (Salatiga); field assistance from NTT Provincial Health Office in West Timor and Kebumen District Health Office, Central Java are much appreciated.

\section{References}

[1] SEARO, "Malaria situation in SEAR countries: Indonesia," 2009, http://www.searo.who.int/en/Section10/Section21/ Section340_4022.htm.

[2] UNDP, "Indonesia progress report on the millenium development goals 2004," Tech. Rep., United Nation Development Program, Jakarta, Indonesia, 2004.

[3] MoH, "RI-CDC, Malaria Situation in Indonesia-unpublished report," Tech. Rep., Ministry of Health-Directorate of Communicable Disease Control, Jakarta, Indonesia, 2006.

[4] C. O'Connor and A. Soepanto, Illustrated Key to Female Anophelines of Indonesia, Directorate of Communicable Disease, MoH and US Naval Medical Research, Jakarta, Indonesia, 1989.

[5] W. Takken et al., Environmental measures for malaria control in Indonesia. A historical review on species sanitation, Wageningen Agricultural University, Wageningen, The Netherlands, 1990.

[6] F. J. Laihad, "Malaria di Indonesia," in Malaria, Patogenesis, Manifestasi Klinis \& Penanganan, P. N. Harijanto, Ed., pp. 17-25, EGC_-Penerbit Buku Kedokteran, Jakarta, Indonesia, 2000.

[7] P. N. Harijanto, Malaria: Epidemiologi, Patogenesis, Manifestasi Klinis, dan Penanganan, Penerbit Buku Kedokteran EGC, Jakarta, Indonesia, 2000.

[8] N. Becker et al., Mosquitoes and Their Control, Kluver Academic/Plenum Publishers, London, UK, 2003.

[9] J. Chin, Control of Communicable Diseases Manual: An Official Report of the American Public Health Association, American
Public Health Association, Washington, DC, USA, 17th edition, 2000 .

[10] L. J. Bruce-Chwatt, Essential Malariology, William Heinnemann Medical Books Ltd., London, UK, 1980.

[11] A. A. Sandosham, Malariology, with Special Reference to Malaya, Singapore University Press, Singapore, 1965.

[12] D. A. Warrell and H. M. Gilles, Essential Malariology, Arnold, London, UK, 4th edition, 2002.

[13] M. T. Gillies, "The problem of exophily in Anopheles gambiae," Bulletin of the World Health Organization, vol. 15, no. 3-5, pp. 437-449, 1956.

[14] E. Ndoen, C. Wild, P. Dale, N. Sipe, and M. Dale, "Relationships between anopheline mosquitoes and topography in West Timor and Java, Indonesia," Malaria Journal, vol. 9, no. 1, article 242, 2010.

[15] E. Ndoen, C. Wild, P. Dale, N. Sipe, and M. Dale, "Dusk to dawn activity patterns of anopheline mosquitoes in West Timor and Java, Indonesia," Southeast Asian Journal of Tropical Medicine and Public Health, vol. 42, no. 3, pp. 550-561, 2011.

[16] E. Ndoen, "Environmental factors and an eco-epidemiological model of malaria in Indonesia," in Griffith School of Environment, p. 323, Griffith University, Brisbane, Australia, 2008.

[17] WHO, "Malaria entomology and vector control-Learner's guide," Tech. Rep., World Health Organization, Geneva, Switzerland, 2003.

[18] WHO, "Malaria entomology and vector control-Tutor's guide," Tech. Rep., World Health Organization, Geneva, Switzerland, 2003.

[19] G. Davidson, "Estimation of the survival-rate of anopheline mosquitoes in nature," Nature, vol. 174, no. 4434, pp. 792-793, 1954.

[20] A. A. Sandosham and V. Thomas, Malariology, with Special Reference to Malaya, Singapore University Press, Singapore, 1983.

[21] G. B. White, "The importance of Anopheles leucosphyrus group mosquitoes as vectors of malaria and filariasis in relation to transmigration and forestry in Indonesia, with assessment of Anopheles balabacensis ecology and vectorial capacity,” Tech. Rep., WHO-VBCRU, Jakarta, Indonesia, 1983.

[22] D. Susanna, "Dinamika Penularan Malaria di Ekosistem Persawahan, Perbukitan, dan Pantai (Studi di Kabupaten Jepara, Purworejo, dan Kota Batam)," in Postgraduate Program, Faculty of Public Health-Doctoral Progam in Public Health, University of Indonesia, Jakarta, Indonesia, 2005.

[23] S. C. Oaks et al., "Malaria-obstacles and opportunities-a report of the Committee for the Study on Malaria Prevention and Control: status review and alternative strategies," Institute of Medicine, National Academy Press, Washington, DC, USA, 1991.

[24] M. W. Service and H. Towson, "The Anopheles vector," in Essential Malariology, D. A. Warrell and H. M. Gilles, Eds., pp. 59-84, Arnold, London, UK, 2002.

[25] T. S. Detinova, "Age-grouping methods in Diptera of medical importance with special reference to some vectors of malaria," Monograph Series. World Health Organization, vol. 47, pp. 13191, 1962. 


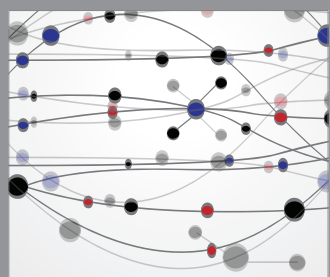

The Scientific World Journal
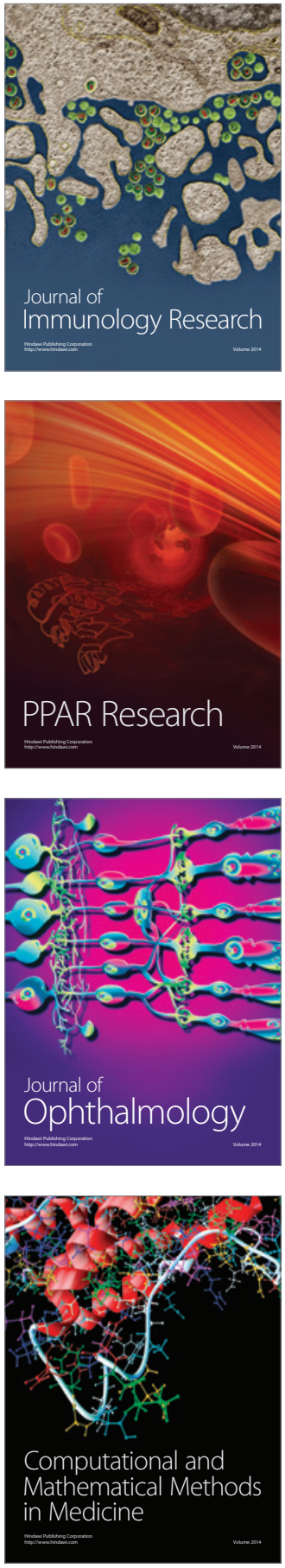

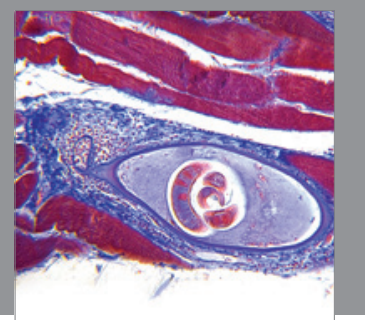

Gastroenterology

Research and Practice
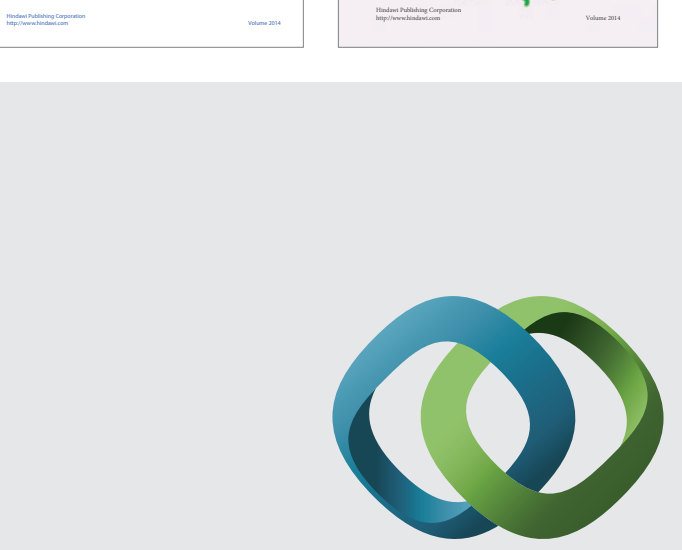

\section{Hindawi}

Submit your manuscripts at

http://www.hindawi.com
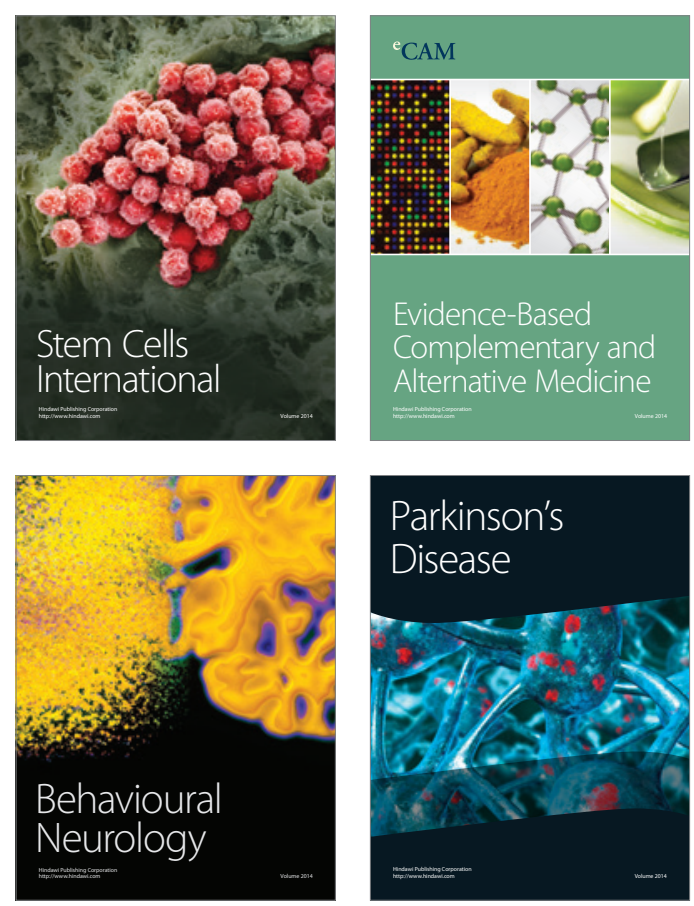

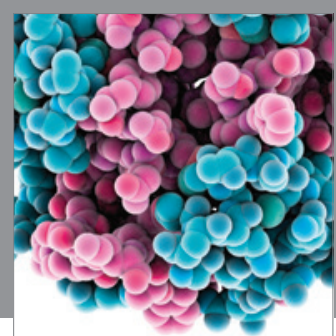

Journal of
Diabetes Research

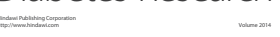

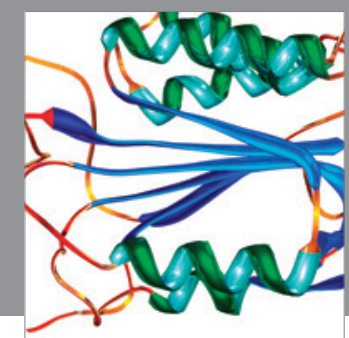

Disease Markers
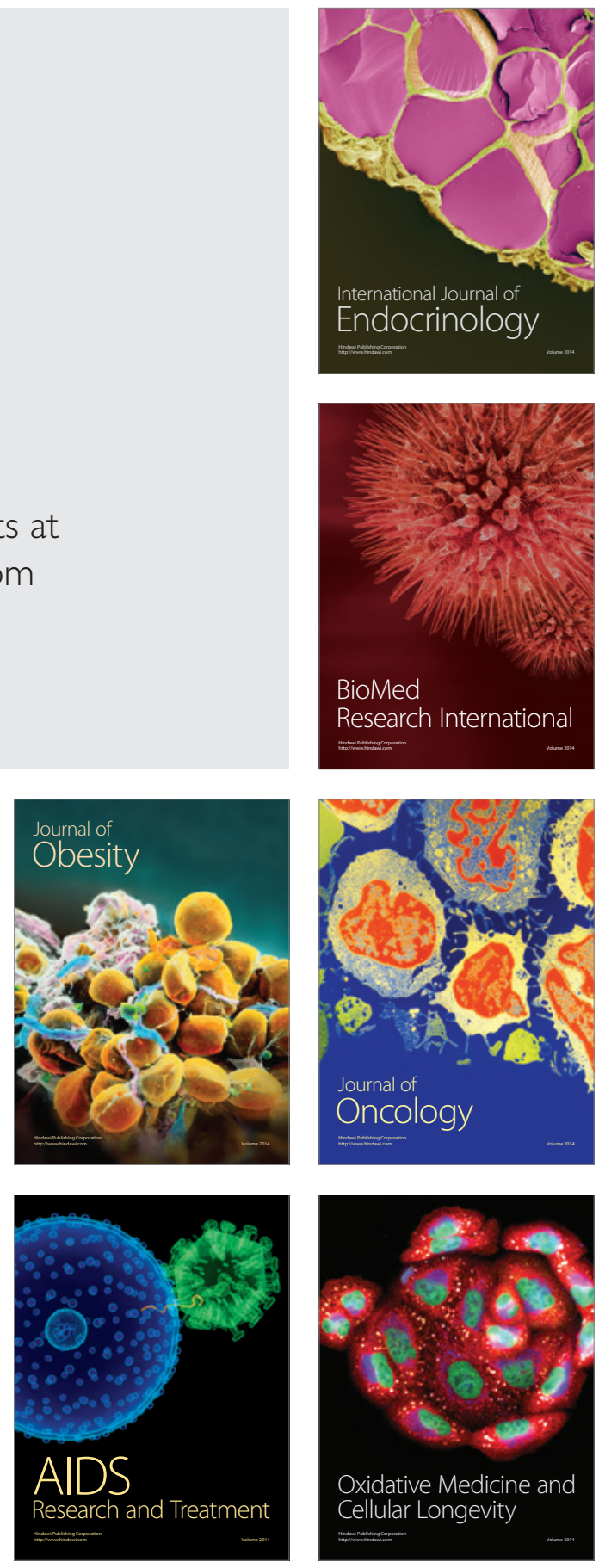